\title{
ALY, a context-dependent coactivator of LEF-1 and AML-1, is required for TCR $\alpha$ enhancer function
}

\author{
Laurakay Bruhn, Audrey Munnerlyn, and Rudolf Grosschedl ${ }^{\mathbf{1}}$ \\ Howard Hughes Medical Institute and Departments of Microbiology and Biochemistry, University of California, San \\ Francisco, California 94143-0414 USA
}

\begin{abstract}
LEF-1 is a transcription factor that participates in the regulation of the T-cell receptor $\alpha$ (TCR $\alpha$ ) enhancer by facilitating the assembly of multiple proteins into a higher order nucleoprotein complex. The function of LEF-1 is dependent, in part, on the HMG domain that induces a sharp bend in the DNA helix, and on an activation domain that stimulates transcription only in a specific context of other enhancer-binding proteins. With the aim of gaining insight into the function of context-dependent activation domains, we cloned ALY, a novel LEF-1-interacting protein. ALY is a ubiquitously expressed, nuclear protein that specifically associates with the activation domains of LEF-1 and AML-1 (CBF 2 2, PEBP2 $\alpha B$ ), which is another protein component of the TCR $\alpha$ enhancer complex. In addition, ALY can increase DNA binding by both LEF-1 and AML proteins. Overexpression of ALY stimulates the activity of the TCR $\alpha$ enhancer complex reconstituted in transfected nonlymphoid HeLa cells, whereas down-regulation of ALY by anti-sense oligonucleotides virtually eliminates TCR $\alpha$ enhancer activity in T cells. Similar to LEF-1, ALY can stimulate transcription in the context of the TCR $\alpha$ enhancer but apparently not when tethered to DNA through an heterologous DNA-binding domain. We propose that ALY mediates context-dependent transcriptional activation by facilitating the functional collaboration of multiple proteins in the TCR $\alpha$ enhancer complex.
\end{abstract}

[Key Words: LEF-1; AML-1/CBF $\alpha 2, \mathrm{PEBP} 2 \alpha \mathrm{B})$; TCR $\alpha$ enhancer; ALY; transcription activation]

Received October 10, 1996; revised version accepted January 30, 1997.

Cell type-specific gene expression is governed by complex cis-acting control regions that are composed of multiple DNA-binding sites for transcription factors, allowing for diversity and accuracy in transcriptional regulation. Both protein-DNA and protein-protein interactions are thought to contribute to the specificity of assembly and function of higher order nucleoprotein complexes. Typical transcriptional activators contain two, often separable, functional domains: one that mediates sequence-specific DNA binding and one that mediates the actual trans-activation event (Ptashne 1988). Another class of transcriptional regulatory proteins, referred to as architectural factors, are DNA-binding proteins that induce directed bends in DNA and facilitate interactions between proteins bound at nonadjacent sites within complex regulatory DNA elements (for review, see Tiian and Maniatis 1994; Grosschedl 1995). One of the founding members of this group is lymphoid enhancer-binding factor 1 (LEF-1), a member of the family of high mobility group (HMG) domain proteins (Travis et al. 1991; Waterman et al. 1991; Landsman and Bustin 1993; Grosschedl et al. 1994). The HMG domain

${ }^{1}$ Corresponding author.

E-MAIL rgross@itsa.ucsf.edu; FAX (415) 476-8201. of LEF-1 binds to a specific nucleotide sequence predominantly through the minor groove of DNA and induces a sharp $120^{\circ} \mathrm{C}$ bend in the DNA helix (Giese et al. 1992; Love et al. 1995). Functionally, LEF-1 is not capable of activating transcription directly from multimerized binding sites but operates when bound to DNA within the context of specific arrangements of other factor-binding sites (Waterman and Jones 1990; Travis et al. 1991).

The mechanistic role of LEF-1 in mediating cell typespecific transcription in a natural context has been explored in detail at the T-cell receptor $\alpha$ (TCR $\alpha)$ enhancer and at the human immunodeficiency virus (HIV) enhancer (Giese et al. 1995; Sheridan et al. 1995). The 112bp minimal TCR $\alpha$ enhancer contains a centrally located LEF-1-binding site, an upstream binding site for a member of the activating transcription factor/cAMP response element-binding (ATF/CREB) family, and three downstream binding sites for two different lymphoid-specific factors (Ho and Leiden 1990; Giese et al. 1995). Two of the downstream sites bind members of the acute myeloid leukemia factor (AML) family, also termed corebinding factor ( $\mathrm{CBF} \alpha$; Wang et al. 1993) or polyoma enhancer-binding protein 2 (PEBP2 $\alpha$; Ogawa et al. 1993a). Two isoforms of AML are lymphoid specific, AML-1 
$(\mathrm{CBF} \alpha 2, \mathrm{PEBP} 2 \alpha \mathrm{B})$ and AML-3 $(\mathrm{CBF} \alpha 1, \mathrm{PEBP} 2 \alpha \mathrm{A})$, and one, AML-2 (CBF $\alpha 3$, PEBP $2 \alpha C)$, is expressed ubiquitously (Ogawa et al. 1993a; Wang et al. 1993; Bae et al. 1994, 1995; Levanon et al. 1994). The AML-binding sites in the TCR $\alpha$ enhancer are located adjacent to a binding site for Ets-1 at the $3^{\prime}$ end of the enhancer. Although AML proteins cooperate with Ets-1 to bind DNA, the ternary complex is unstable in vitro and shows little ability to activate transcription in vivo/Giese et al. 1995). Studies of the TCR $\alpha$ enhancer have revealed two distinct context-dependent functions of LEF-1, an architectural function and a transcription activation function. The architectural role of LEF-1 is mediated by the HMG domain that, by inducing a directed DNA bend in the enhancer, is thought to facilitate interactions between factors bound at the ATF/CREB-binding sites and AML: Ets-binding sites, which are necessary for the formation of a stable enhancer complex (Giese et al. 1995).

The context-dependent transcription activation functions of LEF-I are mediated by regions outside of the carboxy-terminally located HMG domain. Analysis of chimeric proteins in which the HMG domain of LEF-1 was replaced by heterologous DNA-binding domains delineated a context-dependent activation domain (CAD) between residues 99 and 217 of LEF-1 (Carlsson et al. 1993; Giese and Grosschedl 1993). This region differs from typical activation domains in that it is unable to stimulate transcription from multimerized binding sites but rather, activates transcription when tethered to DNA in the context of the natural arrangement of factorbinding sites in the TCR $\alpha$ enhancer or the HIV enhancer (Carlsson et al. 1993; Giese and Grosschedl 1993; Sheridan et al. 1995).

A molecular explanation for the function of the context-dependent activation domain of LEF-1 remains unclear. One simple model is that these regions interact, directly or indirectly, with other enhancer-bound factors. Previous attempts to identify direct LEF-1 interactions with other known TCR $\alpha$ enhancer-binding factors have been unsuccessful (Giese et al. 1995). Here we used a yeast two-hybrid screen to isolate LEF-1-interacting proteins that may contribute to its transcription activation functions. We have identified a novel, nuclear protein that interacts with two TCR $\alpha$ enhancer-bound factors, LEF-1 and AML-1. We show that this factor is required for TCR $\alpha$ enhancer function in T cells and plays a role in regulating the activity of this multiprotein enhancer complex.

\section{Results}

Cloning of cDNAs encoding LEF-1-interacting proteins

To identify proteins that interact and functionally collaborate with LEF-1, we used the yeast two-hybrid assay (Fields and Song 1989). For the screen, we used a LEF-1LexA fusion protein in which the HMG domain of LEF-1 was replaced with the DNA-binding domain of LexA (Giese and Grosschedl 1993). We screened an embryonic day 10 mouse cDNA library in which the cDNA inserts are fused to sequences encoding a VP16 transcription activation domain (Hollenberg et al. 1995). From $-2.7 \times 10^{6}$ yeast transformants, eight library plasmids were isolated that conferred reporter gene activation only in combination with the LEF-1-LexA fusion construct but not with three control LexA fusion proteins, lamin, Ste3, and Fus1. Four of these contained identical inserts of $230 \mathrm{bp}$ and one contained a longer 310-bp insert from the same gene.

The 310-bp insert was used as a probe to isolate fulllength 1.1-kb cDNA clones that encode 255 amino acids followed by stop codons in all three reading frames (Fig. 1). On the basis of its ability to interact with LEF-1 and AML-1 (see below), we refer to the protein product of this cDNA as ALY (Ally of AML-1 and LEF-1). The size of the open reading frame (ORF) of the ALY cDNA corresponds well with the $32-\mathrm{kD}$ molecular mass of recombinant ALY polypeptide transcribed and translated in vitro (see Fig. 3B, below), and with the size of the endogenous protein that can be detected on immunoblots by polyclonal antibodies directed against ALY (data not shown).

Amino acid sequence comparison of ALY with proteins in the GenBank database revealed no identities but did reveal potential homology with RNA-binding proteins. In particular, the protein contains a putative RNP (ribonucleoprotein) RNA recognition motif and Arg/

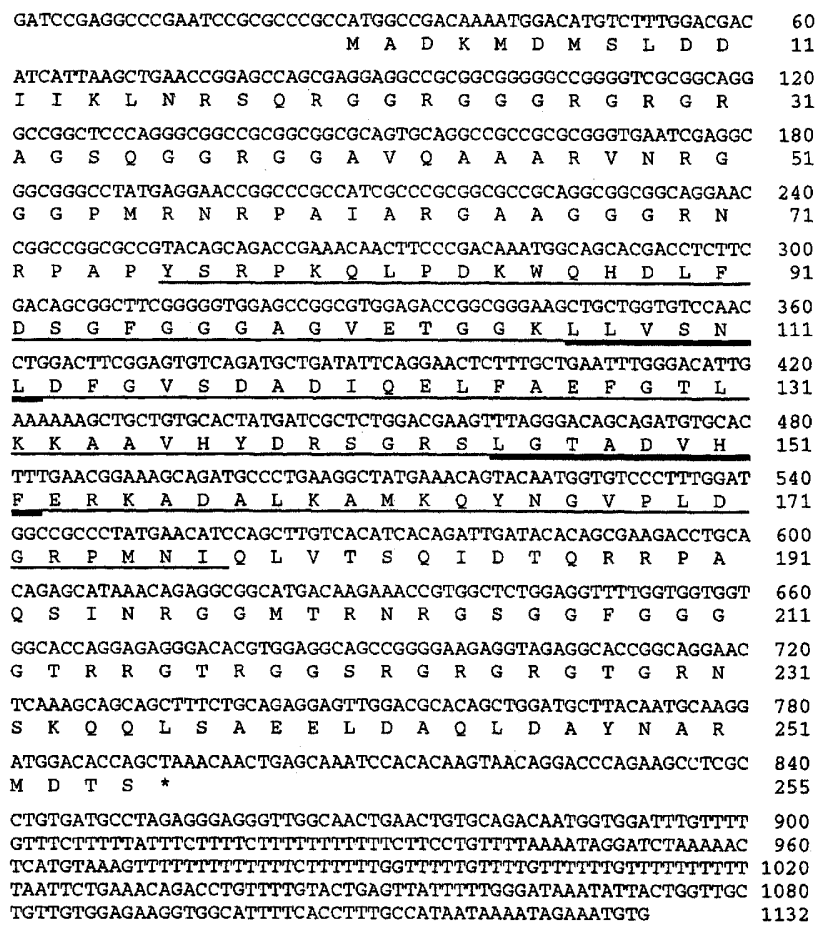

Figure 1. Nucleotide sequence of the murine ALY cDNA and predicted amino acid sequence of the encoded protein. The polypeptide encoded by the 310-bp two-hybrid isolate, termed ALY $\triangle N C$, is underlined. This underlined region encompasses the putative RNP (ribonucleoprotein) RNA-binding motif. The putative RNP1 (RNP octamer) and RNP2 (RNP hexamer) sequences are underlined in bold. 
Gly-rich regions in the amino and carboxyl termini that are loosely homologous to RGG RNA-binding motifs (for review, see Burd and Dreyfuss 1994). Biochemical and structural studies of RNP domains have shown that they are sufficient to mediate RNA binding and that three highly conserved aromatic amino acids found in the RNP1 (RNP octamer) and RNP2 (RNP hexamer) sequences are involved in critical stacking interactions with RNA bases (for review, see Nagai et al. 1995). However, the putative RNP1 and RNP2 sequences of ALY (Fig. 1, bold underlined) contain only a single aromatic amino acid. Moreover, preliminary studies demonstrated that ALY $\triangle N C$, which includes the putative RNP domain, is not capable of binding RNA at any detectable level, although very weak nonspecific binding to RNA and DNA was observed with full-length ALY protein (data not shown). Thus, ALY may represent a protein that is related to RNA-binding proteins and has some propensity to interact with nucleic acids, but in which the RNP domain may perform other functions.

\section{ALY encodes a ubiquitously expressed, nuclear protein}

To examine the expression pattern of $A L Y$, we analyzed poly $(\mathrm{A})^{+}$RNA from various mouse tissues and cell lines for the presence of transcripts that hybridize with an ALY cDNA probe. A single $1.1-\mathrm{kb}$ ALY transcript was detected at varying levels in all tissues and cell lines examined suggesting that $A L Y$ may be expressed ubiquitously (Fig. 2). The subcellular localization of ALY was examined by indirect immunofluorescence microscopy of COS7 cells that had been transfected transiently with a plasmid expressing a T7 epitope-tagged version of ALY. This approach was necessary because our anti-ALY antiserum failed to recognize native protein (data not shown). By comparing the immunofluorescence staining of T7-ALY with DAPI staining of DNA, we detected ALY primarily in the nucleus of transfected cells (Fig. $2 C, D)$. We conclude from these results that ALY is a ubiquitously expressed nuclear protein.

\section{ALY interacts with $L E F-1$ and $A M L$ proteins}

To establish that full-length ALY can interact directly with LEF-1, we performed in vitro association assays with purified recombinant glutathionine $S$-trasferase (GST)-ALY fusion protein. ${ }^{35} \mathrm{~S}$-Labeled LEF-1 protein was bound by immobilized GST-ALY but not GST alone (Fig. 3A, lane 2). Because ALY contains regions with some homology to RNA-binding domains, it was possible that the ALY:LEF-1 interaction was mediated indirectly by nucleic acids. However, inclusion of ethidium bromide in the GST association experiments, which has been shown to disrupt potential nonspecific interactions caused by contaminating nucleic acids (Lai and Herr 1992), and preincubation of GST-ALY and the ${ }^{35}$ S-labeled proteins with RNase did not affect the association of GST-ALY with LEF-1 (data not shown).

Previous studies suggested that the function of LEF-1, in particular the CAD, could involve interactions with
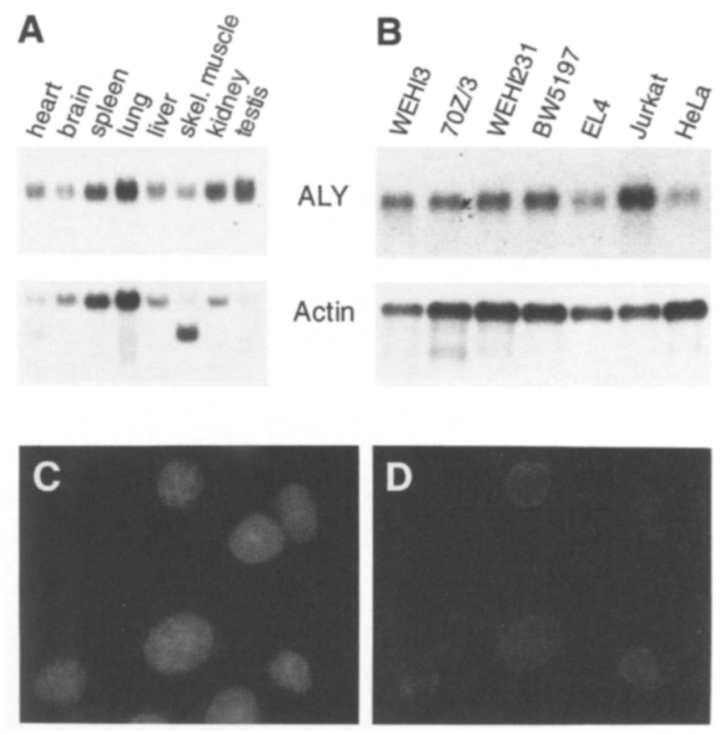

Figure 2. ALY is expressed ubiquitously and localized to the nucleus. $(A, B)$ RNA blot analysis of ALY transcripts in adult mouse tissues and various cell lines. Cell lines include mouse myeloid (WEHI3), bone marrow-derived pre-B cells (70Z/3), B cells (WEHI231), and CD4 ${ }^{-} / \mathrm{CD}^{-} \mathrm{T}$ cells (BW5197 and EL4). $\mathrm{HeLa}$ and Jurkat are human cervical carcinoma and T-cell lines, respectively. The size of the ALY mRNA is $1.1 \mathrm{~kb}$ as determined by comparison with RNA size markers. To control for RNA levels, the same blot was rehybridized with a mouse actin gene probe (bottom). (C,D) Immunocytochemical staining of T7 epitope-tagged ALY expressed by transient transfection in COS7 cells. DAPI fluorescence $(C)$ and FITC immunofluorescence $(D)$ microscopy of the same field of fixed COS7 cells reacted with T7 monoclonal antibodies and double stained with FITC-conjugated goat anti-mouse antibodies and the DNA intercalating agent DAPI. Note that, because the T7-ALY expression plasmid was introduced by transient transfection, we do not detect $\mathrm{T} 7$. tagged ALY in all cells.

other transcriptional regulators of the TCR $\alpha$ enhancer (Travis et al. 1991; Carlsson et al. 1993; Giese and Grosschedl 1993). We tested the ability of GST-ALY to interact with various ${ }^{35} \mathrm{~S}$-labeled transcription factors including those that are known to bind the TCR $\alpha$ enhancer (Fig. 3A). Strikingly, in addition to LEF-1 (lane 2), GSTALY interacted specifically with AML-3 (lane 3) and AML-1 (see below). In contrast, GST-ALY did not detectably associate with $\mathrm{CBF} \beta$ (lane 4), the heterodimeric binding partner of AML proteins (Ogawa et al. 1993b; Wang et al. 1993) and failed to interact with Ets-1 or an amino-terminally truncated derivative of Ets-1 (lanes $7,8)$, which was shown to interact strongly with AML-3 (PEBP2 $\alpha$ A, CBF $\alpha 1$; Giese et al. 1995). Members of the ATF/CREB family including ATF-2, CREB-B, and c-lun, also failed to interact strongly with GST-ALY, although a very low level of binding of CREB-B and c-Jun was observed (lane 6; data not shown). This weak interaction of ALY with CREB-B was unaffected by phosphorylation of CREB-B by protein kinase A (data not shown), which was found previously to regulate its association with the 
A

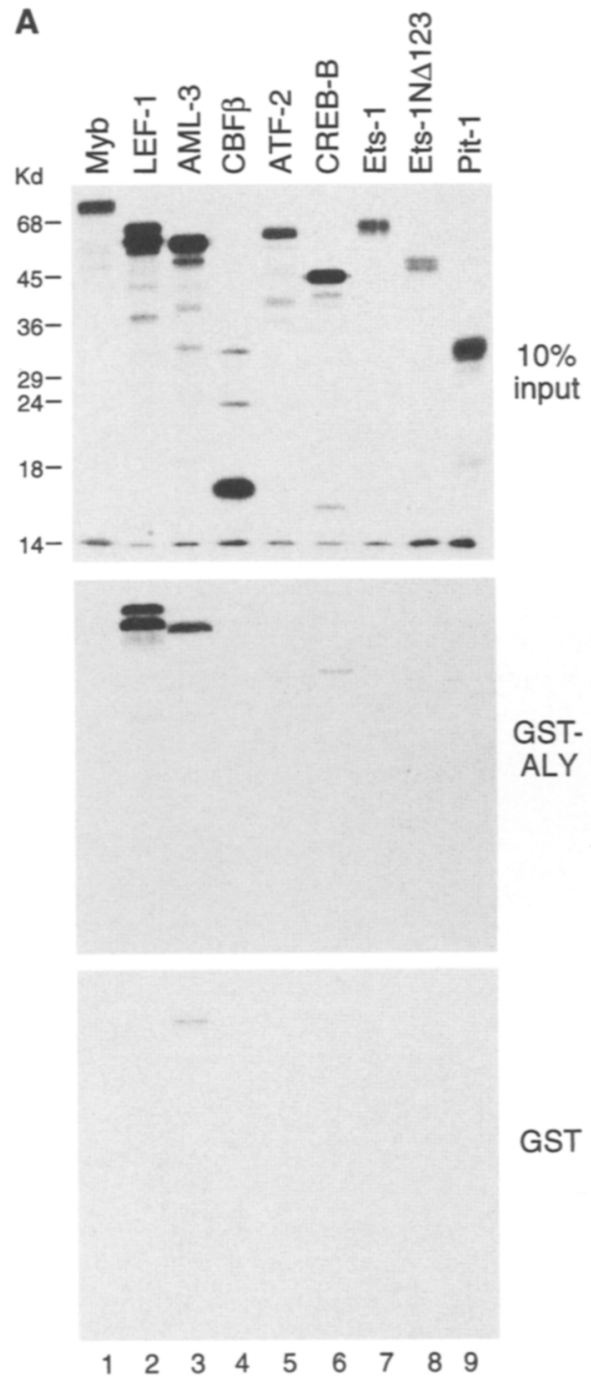

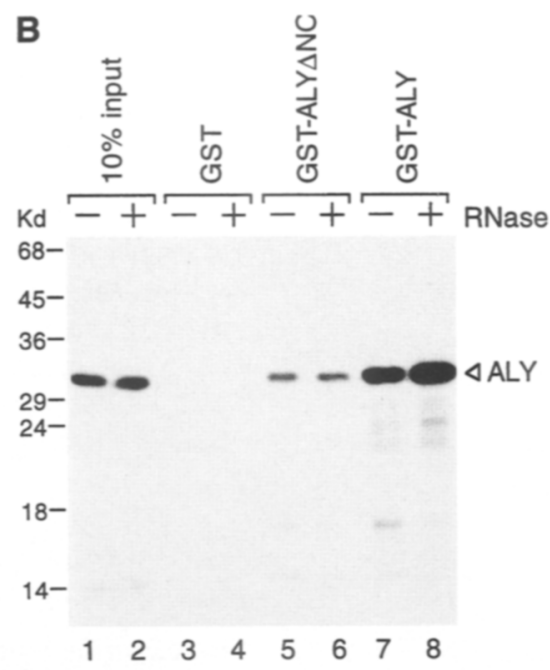

Figure 3. ALY interacts specifically with LEF-1, AML proteins, and itself. (A) In vitro association assays between GSTALY (middle) and GST (bottom) immobilized on glutathione agarose beads with in vitro translated ${ }^{35} \mathrm{~S}$-labeled proteins including full-length $\mathrm{cMyb}$, LEF-1, CBF $\beta$, ATF- $2_{195}$ isoform, CREB-B, Ets-1, and Pit1. AML-3 lacks the amino-terminal 94 residues and Ets-1-N $\Delta 123$ lacks the amino-terminal 123 residues. Ten percent of input radiolabeled proteins (top) and bound proteins were analyzed by SDSPAGE and visualized by autoradiography. Molecular size markers are shown in kilodaltons. $(B)$ In vitro association assays between in vitro-translated ${ }^{35}$ S-labeled ALY protein and GST, GST-ALY $\triangle N C$, and GST-ALY. Immobilized GST proteins and the in vitro-translated proteins were preincubated with RNase as indicated. coactivator CREB-binding protein (CBP) (Kwok et al. 1994). Two other transcription factors-Myb, which collaborates with AML proteins to activate the TCR $\beta$ enhancer (Hernandez-Munain and Krangel 1995), and Pit-1, which contains a functional domain with homology to the CAD of LEF-1 (Holloway et al. 1995)-also failed to associate detectably with GST-ALY (Fig. 3A, lanes 1,9). These results were confirmed by reciprocal associations that demonstrated that ${ }^{35} \mathrm{~S}$-labeled ALY could bind to immobilized GST-LEF-1 and GST-AML-3, but not significantly to GST-CBF $\beta$, GST-Ets-1, or GST-ATF2 (data not shown).

To examine whether ALY has the potential to multimerize, we incubated ${ }^{35}$ S-labeled ALY with immobilized GST-ALY and GST-ALYANC (Fig. 3B). Association was detected only with GST-ALY indicating that ALY can multimerize primarily through regions at the amino or carboxyl terminus of the protein. As for the interaction of ALY with LEF-1 and AML proteins, RNase treatment of the protein preparations did not affect the associations (Fig. 3B; data not shown). The finding that ALY may function as a multimer could allow, in principle, for simultaneous interactions between ALY and multiple factors in the enhancer complex even if the interactions with different factors were mediated by the same region of ALY.

Mapping the protein domains required for interaction of $A L Y$ with $L E F-1$ and $A M L-1$

To begin to map the protein domains required for the ALY:LEF-1 interaction, we tested the ability of GSTALY and GST-ALY $\triangle N C$ to interact with various aminoand carboxy-terminally truncated versions of LEF-1 (Fig. 4). Amino-terminal truncation of residues between 99 and 166, which coincide with the CAD of LEF-1/Carlsson et al. 1993; Giese and Grosschedl 1993|, completely abrogated binding to GST-ALY $\triangle N C$ and reduced binding to GST-ALY 5- to 10-fold. A form of LEF-1, lacking residues downstream of residue 243 , showed increased 

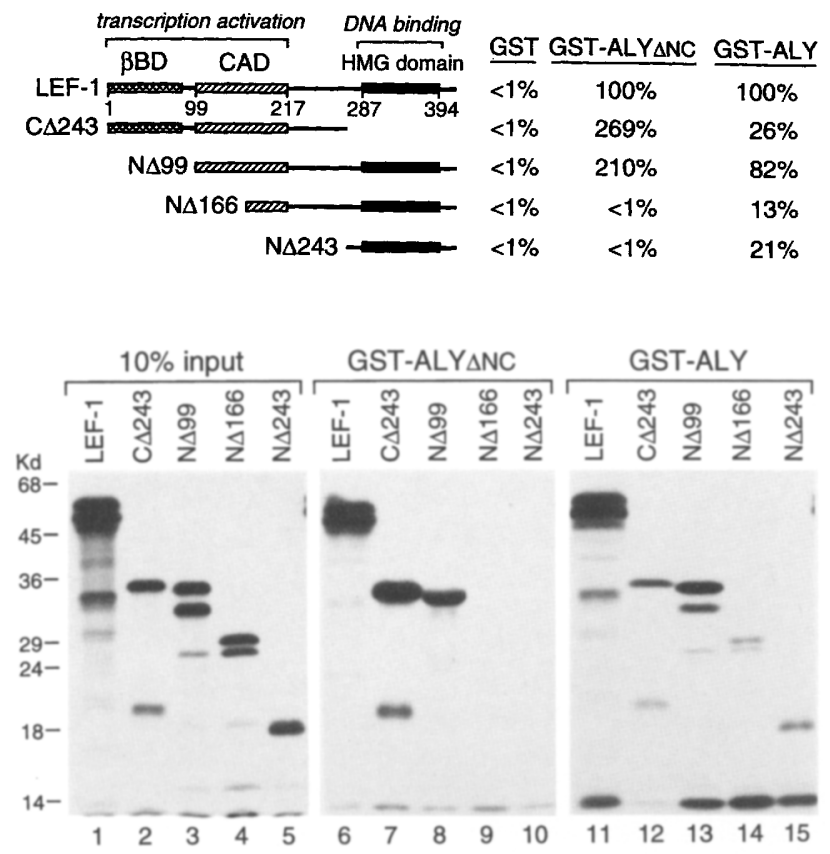

Figure 4. ALY interacts with the context-dependent activation and HMG domains of LEF-1. Schematic diagrams of LEF-1 and deletion derivatives (top). The $\beta$-catenin-binding domain $(\beta B D)$, context-dependent activation domain $(\mathrm{CAD})$, and high mobility group (HMG) domain are boxed. Association assays between in vitro-translated ${ }^{35}$ S-labeled LEF-1 polypeptides (lanes 1-5, 10\% of input) and GST-ALY DNC (lanes 6-10) or GST-ALY (lanes 11-15) immobilized on glutathione-agarose beads. Similar molar amounts, normalized for the number of ${ }^{35}$ S-labeled methionines, of labeled full-length and truncated versions of LEF-1 were used in the association reactions. The input and the bound proteins were analyzed by SDS-PAGE and visualized by autoradiography. The amounts of ${ }^{35}$ S-labeled proteins bound to GST, GST-ALY $\triangle N C$, and GST-ALY were quantified from the association experiment shown at bottom using a Phosphorlmager (Molecular Dynamics) and are presented as percentages relative to the amount of bound full-length LEF-1, which was designated as $100 \%$ (top). Similar results were obtained in three independent association experiments.

binding to GST-ALY $\triangle N C$ but reduced binding to GSTALY. Thus, the amino- or carboxy-terminal regions of ALY may mediate interactions with the HMG domain and the central region of ALY may associate with the CAD of LEF-1.

Previous studies delineated the DNA-binding domain of AML-1 and AML-3, termed the Runt domain, to the amino-terminal half of the proteins. The carboxy-terminal half of AML proteins is required for its ability to function as a transcription activator both at the TCR $\beta$ enhancer (Bae et al. 1994) and the TCR $\alpha$ enhancer (L. Bruhn, unpubl.). Similar to LEF-1, AML proteins activate transcription in the context of other factor-binding sites but not from multimerized sites (Y. Ito, pers. comm.). As expected from the high degree of homology between the AML proteins, GST-ALY bound with similar efficiency to AML-3 (Fig. 3A) and AML-1 (Fig. 5). Truncation of residues carboxy-terminal to 287 of AML-1 decreased the association with GST-ALYANC by a factor of 20. Deletion of all residues downstream of the Runt domain completely abrogated the interaction of full-length GSTALY with AML-1. Analysis of the interaction of GSTALY and GST-ALY $\triangle N C$ with the corresponding deletion derivatives of AML-3 yielded similar results (data not shown). Thus, ALY interacts with two regions within the carboxy-terminal half of AML-1 that contains a CAD, but not with the Runt domain that has been shown to interact with CBF (Ogawa et al. 1993b; Wang et al. 1993), Ets-1 (Giese et al. 1995), and CCAAT enhancer-binding protein (C/EBP) (Zhang et al. 1996).

\section{ALY augments DNA binding by full-length LEF-1 and $A M L$ proteins}

To examine whether ALY can interact with DNA-bound LEF-1 or AML proteins, we used an electrophoretic mobility-shift assay with the 98-bp TCR $\alpha$ enhancer probe.
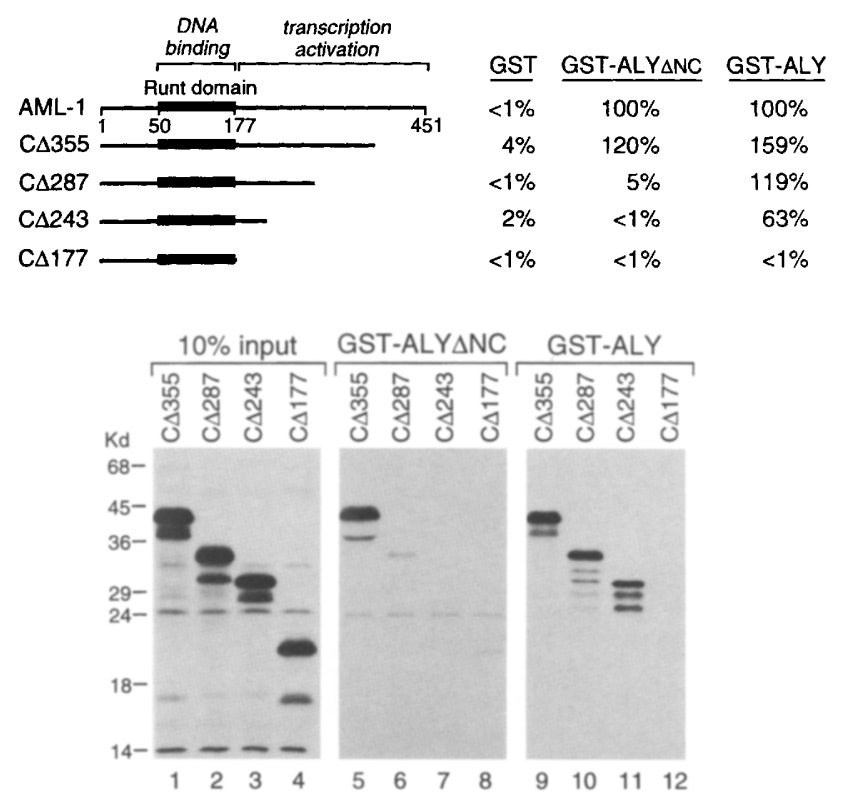

Figure 5. ALY interacts with the transcription activation domain of AML-1. Schematic diagrams of AML-1 and deletion derivatives (top). The Runt domain that mediates DNA binding and interaction with CBF $\beta$, Ets-1, and C/EBP is represented by a solid rectangle. Association assays between in vitro-translated ${ }^{35} \mathrm{~S}$-labeled AML-1 polypeptides (lanes $1-4,10 \%$ of input) and GST-ALY $\triangle N C$ (lanes 5-8) or GST-ALY (lanes 9-12) immobilized on glutathione agarose beads. Similar molar amounts, normalized for the number of ${ }^{35} \mathrm{~S}$-labeled methionines, of labeled full-length and truncated versions of AML-1 were used in the association reactions. The input and bound proteins were analyzed by SDS-PAGE and visualized by autoradiography. The amounts of ${ }^{35} \mathrm{~S}$-labeled proteins bound to GST, GST-ALY $\triangle N C$, and GST-ALY were quantified from the association experiment shown at bottom using a PhosphorImager (Molecular Dynamics) and are presented as percentages relative to full-length AML-1, which was designated as $100 \%$ (top). Similar results were obtained in three independent association experiments. 
Incubation of recombinant purified LEF-1 with high concentrations of purified GST-ALY yielded a complex that migrated with a slower mobility than that formed with LEF-1 alone, consistent with the formation of a ternary ALY:LEF-1:DNA complex (Fig. 6A, lane 3). No slower migrating complex was detected when GST-ALY was coincubated with the HMG domain (Fig. 6A, lane 7). In addition, GST-ALY had no detectable DNA-binding activity by itself in this assay (Fig. 6A, lanes 10-12). Notably, ALY increased DNA binding approximately fivefold by full-length LEF-1 and the HMG domain, both of which interact with ALY. In contrast, GST-ALY $\triangle N C$, at a 10-fold higher concentration, had no effect on DNA binding by LEF-1 or the HMG domain (data not shown). A recombinant purified hexa-histidine-tagged version of

A
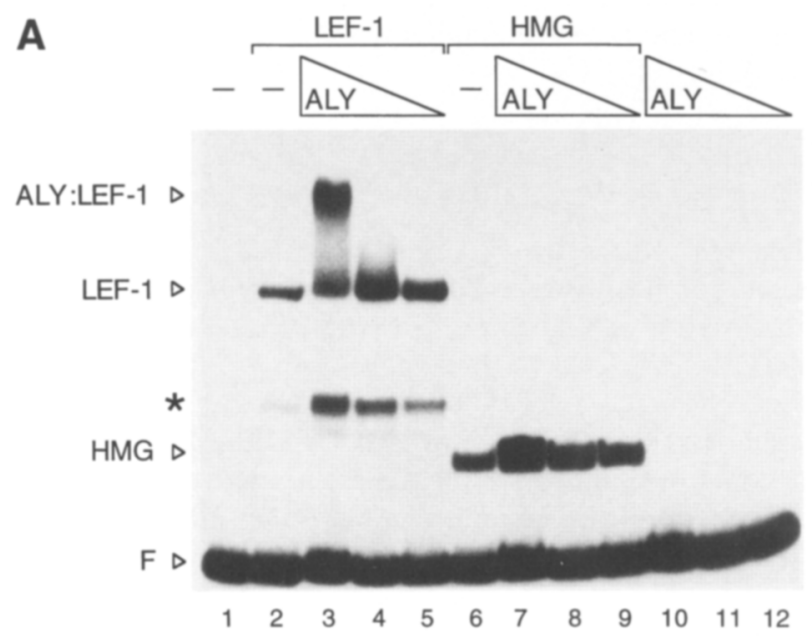

B
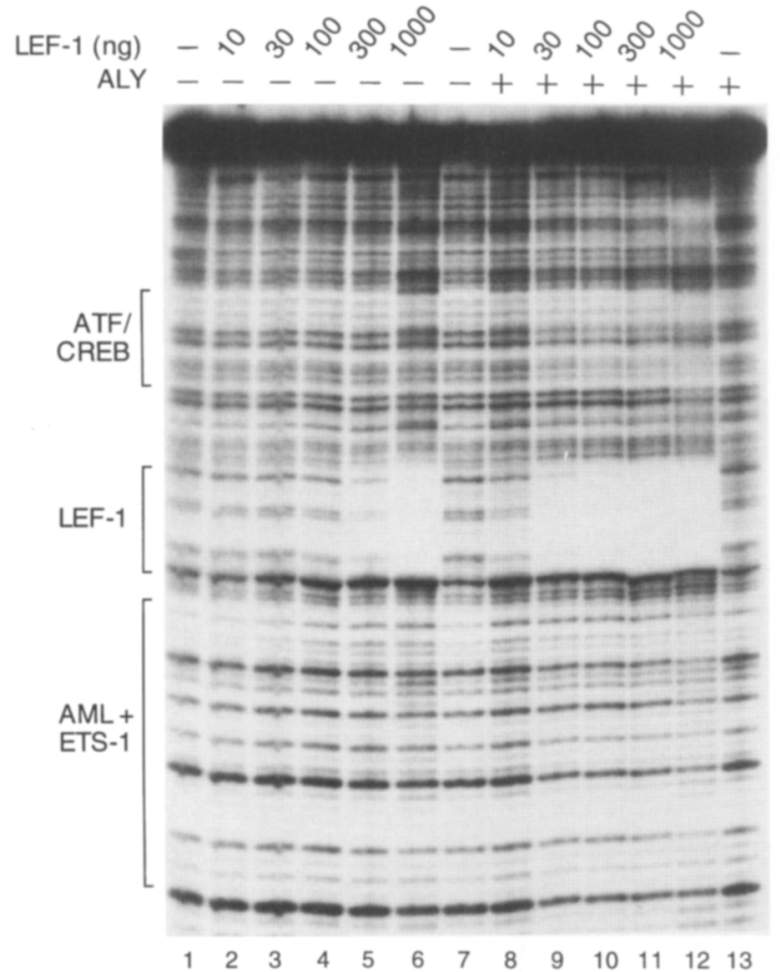

ALY had similar effects as GST-ALY on DNA-binding by LEF-1 (data not shown).

The ternary ALY:LEF-1:DNA complex formed with the 98-bp TCR $\alpha$ enhancer probe but not with a 50-bp TCR $\alpha$ enhancer probe lacking sequences upstream of the LEF-1 site (Fig. 6A; data not shown). This observation raised the possibility that the formation of a ternary complex may require a particular length or sequence of DNA. In quantitative DNase I protection assays, in which we confirmed the effect of ALY on increasing the efficiency of DNA binding by LEF-1, we did not detect differences in the footprint pattern of the LEF-1:TCR $\alpha \mid 98$ bp) complex in the presence or absence of ALY (Fig. 6B). Thus, this putative ALY:DNA interaction may not involve a specific sequence or may be unstable.

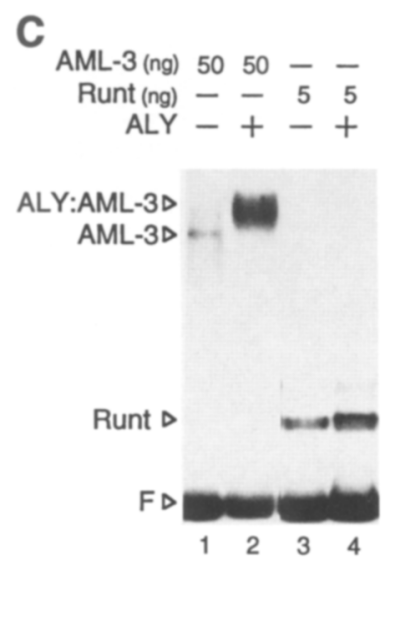

Figure 6. ALY can form a ternary DNA complex with LEF-1 and AML proteins. (A) Electrophoretic mobility-shift assay with recombinant purified LEF-1, HMG, and GST-ALY proteins. A radiolabeled 98-bp TCR $\alpha$ probe was incubated with $1 \mathrm{ng}$ of full-length LEF-1 (lanes 2-5), 1 ng of HMG polypeptide (lanes 6-9), or no LEF-1 (lanes 10-12) in the absence or presence of $2.5 \mu \mathrm{g}$ (lanes 3,7,10), 0.8 $\mu \mathrm{g}$ (lanes 4,8,11), or $0.25 \mu \mathrm{g}$ (lanes 5,9,12) purified GST-ALY protein. Protein-DNA complexes and free probe $(\mathrm{F})$ are indicated by open arrowheads (left). An amino-terminally truncated form present in the purified full-length LEF-1 protein is indicated by an asterisk. $(B)$ DNase I footprint analysis of the 5 '-end-labeled 98-bp TCR $\alpha$ DNA fragment using purified LEF-1 protein in the amounts indicated in the absence $(-)$ or presence $(+)$ of $2.5 \mu \mathrm{g}$ of purified GST-ALY. The brackets indicate the region protected by LEF-1 and the binding sites for ATF/CREB, AML, and Ets-1. $\langle C\rangle$ Electrophoretic mobilityshift assay with recombinant purified AML-3 and GST-ALY proteins. A radiolabeled 98-bp TCR $\alpha$ probe was incubated with $50 \mathrm{ng}$ of AML-3 (residues 94-411) (lanes 1,2) or 5 ng Runt domain of AML-3 (residues 93-226) (lanes 3,4) in the absence or presence of $2.5 \mu \mathrm{g}$ of purified GST-ALY protein. Protein-DNA complexes and free probe (F) are indicated by open arrowheads (left). 
To examine whether ALY has an effect on DNA binding by AML proteins, we incubated the 98-bp TCR $\alpha$ enhancer probe with purified recombinant AML-3, which could be obtained from bacteria in soluble form. A complex that migrated with a slower mobility than the AML3:DNA complex was detected (Fig. 6C). In the ALY: AML-3:DNA ternary complex, DNA binding was increased $\sim 20$-fold. In contrast, coincubation of ALY with the Runt domain of AML-3 increased DNA binding less than twofold and did not result in formation of a detectable ternary complex (Fig. 6C). The Runt domain binds DNA more efficiently than full-length AML-3 protein but does not interact with ALY in the GST association assay. Therefore, the association of AML proteins with ALY may antagonize the function of an inhibitory domain, consistent with the previous observations that carboxy-terminally truncated versions of AML-1 bind DNA with higher affinity than full-length protein (Bae et al. 1994; Tanaka et al. 1995).

\section{ALY specifically stimulates the activity of the TCR $\alpha$ enhancer}

Previously we have found that expression of LEF-1 and the lymphoid-specific factors AML (CBF $\alpha$, PEBP2 $\alpha$ ) and Ets-1 confers high levels of TCR $\alpha$ enhancer activity in nonlymphoid HeLa cells (Giese et al. 1995). Given the lower ALY mRNA levels in HeLa cells compared to most T-cell lines (see Fig. 2B), we used the reconstituted HeLa cell system to determine the effect of ALY overexpression on TCR $\alpha$ enhancer activity. For these and other transfection experiments, we used AML-1, which is expressed in $\mathrm{T}$ cells much more abundantly than AML-3 (Satake et al. 1995). Overexpression of ALY resulted in a dose-dependent increase in the levels of TCR $\alpha$-CAT ex- pression with a maximum of fivefold (Fig. 7A). ALY alone or the truncated ALY $\triangle N C$ in combination with the lymphoid-specific factors had no effect on TCR $\alpha$ enhancer activity.

To determine whether the ALY-mediated increase in reporter gene expression was specific for the TCR $\alpha$ enhancer, we tested three other reporter gene constructs controlled by the cytomegalovirus (CMV), Rous sarcoma virus (RSV), or SV40 viral enhancer/promoter regions, which are activated by endogenous proteins in HeLa cells. In addition, we examined the effect of ALY overexpression on the activity of two reporter genes stimulated by exogenously expressed AP1 or Gal-4-VP16. In these experiments, we transfected minimal amounts of reporter and effector plasmids to ensure that potential ALY-mediated effects on reporter gene activity could be observed. Except for a minor, twofold effect on the SV40controlled reporter gene, the expression levels of all other reporters were unaffected by overexpression of ALY (Fig. 7B).

\section{ALY is required for TCR $\alpha$ enhancer function in $T$ cells}

Although overexpression of ALY resulted in a significant increase in TCR $\alpha$ enhancer activity in HeLa cells, overexpression in $\mathrm{T}$ cell lines conferred negligible increases in TCR $\alpha$ expression (L. Bruhn, unpubl.). This could reflect the higher levels of endogenous ALY transcript present in most $\mathrm{T}$ cell lines (see Fig. 2B). To determine the contribution of ALY to TCR $\alpha$ enhancer activity in T cells in which the enhancer is naturally functional, we attempted to decrease the levels of endogenous ALY protein using C-5 propyne pyrimidine-substituted phosphorothioate anti-sense oligonucleotides (Wagner et al. 1993). Cotransfection of an ALY anti-sense oligonucleo-
Figure 7. ALY stimulates specifically the activity of the TCR $\alpha$ enhancer. (A) Fulllength ALY stimulates TCR $\alpha$ enhancer activity reconstituted in nonlymphoid cells. HeLa cells were transfected with expression plasmids for AML-1 (200 ng), Ets-1 (200 ng), and LEF-1 (100 ng) alone or with different amounts of expression plasmids for ALY or ALY $\triangle N C$ together with $250 \mathrm{ng}$ of a TCR $\alpha$ reporter plasmid. The reporter plasmid (top) contains the minimal 98-bp TCR $\alpha$ enhancer linked to the minimal fos promoter $(-56$ to +109$)$, and the chloramphenicol acetyltransferase (CAT) gene. For these and subsequent transfection assays, luciferase or CAT activity was normalized to the activity of an RSV- $\beta$-gal expression plasmid as an internal transfection standard. Fold activation was quantitated relative to CAT activity from cells transfected with the reporter alone, which was designated as 1. $(B)$ Effects of ALY on other reporter constructs. HeLa cells were transfected with various reporter and effector plasmids in the absence or presence of $500 \mathrm{ng}$ of ALY expression plasmid. Data from TCR $\alpha$-CAT with LEF-1, Ets-1, and AML-1 is duplicated from $A$. The amounts of other reporter and effector plasmids were as follows: $500 \mathrm{ng}$ of CMV-CAT, RSV- $\beta$-gal, or SV40-CAT reporter constructs; $2 \mu \mathrm{g}$ of $(\mathrm{AP} 1)_{1}$-luciferase plus $250 \mathrm{ng}$ each RSV-c-Jun and RSV-c-Fos; $2 \mu \mathrm{g}$ of $(\mathrm{Gal} 4)_{1}$-luciferase plus $250 \mathrm{ng}$ RSV-Gal4-VP16.

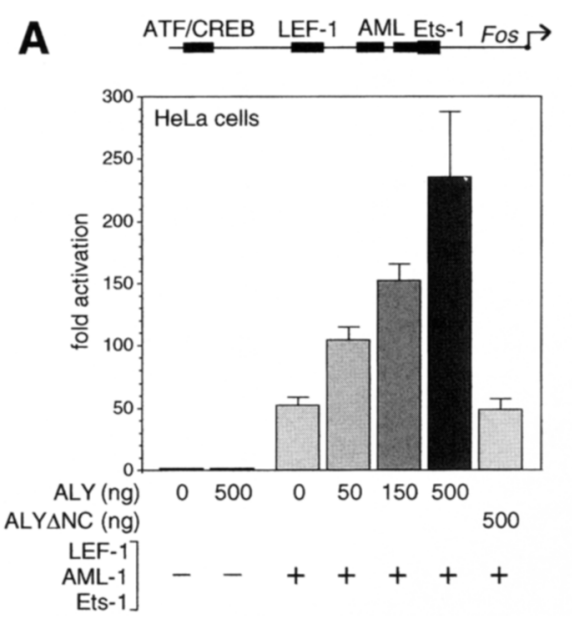

B

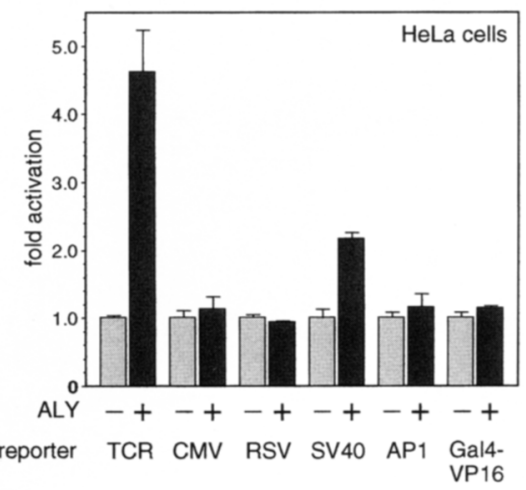


A

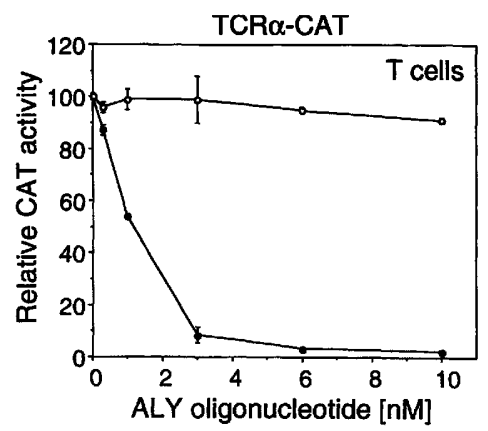

B
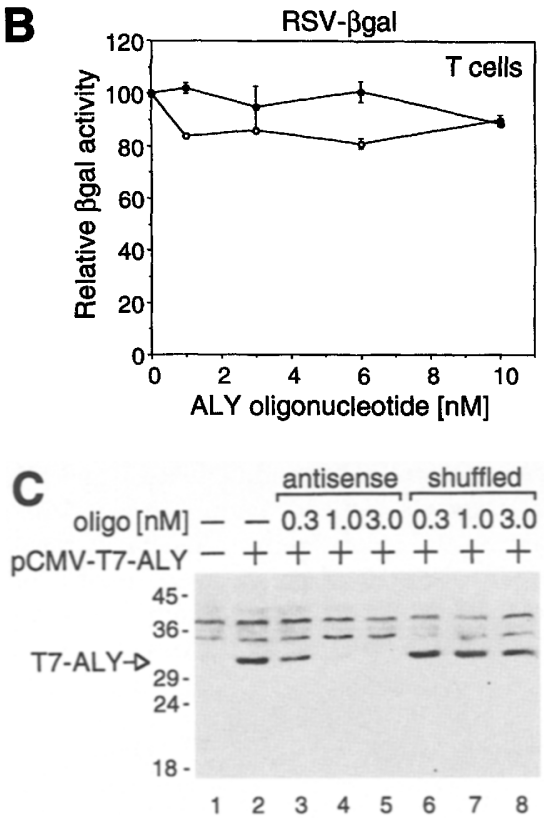

Figure 8. Down-regulation of ALY expression in T cells abrogates TCR $\alpha$ enhancer function. Jurkat $\mathrm{T}$ cells were transfected transiently with $1 \mu \mathrm{g}$ of TCR $\alpha$-CAT $(A)$, RSV- $\beta$-gal $(B)$, or CMV-T7-ALY $(C)$, together with increasing concentrations of ALY anti-sense or shuffled oligonucleotides. The activities of the reporters in the presence of different concentrations of oligonucleotides were calculated relative to that with no oligonucleotide, which was designated as $100 \%$. Whole cell extracts of cells transfected transiently with T7-ALY were analyzed by immunoblot using T7 monoclonal antibody. Data in $A$ and $B$ are the average of at least two transfections carried out in duplicate; error bars represent standard error of the mean.

tide with the TCR $\alpha$-chloramphenicol acetyltransferase (CAT) reporter construct into Jurkat $\mathrm{T}$ cells decreased CAT expression in a dose-dependent manner (Fig. 8A). In contrast, similar concentrations of a shuffled control oligonucleotide had no effect on TCR $\alpha$-CAT expression (Fig. 8A). Importantly, a control reporter, RSV- $\beta$-gal, was unaffected by the ALY anti-sense oligonucleotide demonstrating that its effect is specific for the TCR $\alpha$ enhancer (Fig. 8B). To examine whether transient transfection of ALY anti-sense oligonucleotides actually decreases the concentration of intracellular ALY protein, we cotransfected a plasmid expressing T7-epitope-tagged ALY into Jurkat T cells and examined the levels of T7-
ALY in whole cell extracts by immunoblot analysis. Strikingly, the expression of T7-ALY was decreased in a dose-dependent manner with the ALY anti-sense oligonucleotide but was unaffected by similar concentrations of the shuffled control oligonucleotide (Fig. 8C). Thus, ALY plays an important role in the regulation of the TCR $\alpha$ enhancer.

\section{Transcriptional activation by $A L Y$ is dependent on multiple TCR $\alpha$ enhancer-binding proteins}

One simple model of ALY function is that this protein increases the activity of the TCR $\alpha$ enhancer by providing the enhancer complex with a transcription activation domain through binding to LEF-1. To explore this possibility, we tested whether ALY is capable of activating transcription when tethered to DNA by the Gal4 DNA-binding domain. ALY-Gal4 did not confer activation from multimerized Gal4 sites in transfected $T$ cells and likewise, a LexA-ALY fusion protein did not activate expression of a reporter containing multimerized LexA sites (Fig. 9A; data not shown). In addition, neither ALY-Gal4 nor LexA-ALY fusion proteins significantly activated expression of $\mathrm{TCR} \alpha$ enhancer constructs in which the LEF-1 binding site was replaced with a Gal4 or LexA site (Fig. 9B; data not shown). Efficient expression and DNA binding of the fusion proteins was confirmed by electrophoretic mobility-shift assays with nuclear extracts from COS7 cells transfected with these expression plasmids (Fig. 9C). These data suggest that ALY lacks a typical activation domain and probably does not stimulate TCR $\alpha$ enhancer function by recruitment of a transcription activation domain to the enhancer complex.

The findings that ALY can form multimers and can interact with both LEF-1 and AML proteins raised the possibility that it may serve to functionally bridge these factors within the TCR $\alpha$ enhancer complex. According to this view, the function of ALY in the reconstituted HeLa system would be dependent on both LEF-1 and AML-1. Coexpression of ALY with any two of the three lymphoid-specific factors stimulated the activity of TCR $\alpha$ four- to fivefold, although the levels of reporter expression were $\sim 10$-fold lower than those observed with all three factors (cf. Figs. 7A and 9D). In contrast, no significant ALY stimulation was observed with individual lymphoid-specific factors, with the exception of a twofold ALY stimulation with Ets-1. On basis of the presence of AML-2 (CBF $\alpha 3$, PEBP2 $\alpha C)$ in all cell types, this modest increase of TCR $\alpha$-CAT expression could be attributable to a stimulation by ALY in concert with this endogenous isoform. Consistent with this interpretation, the increase was not observed with a TCR $\alpha$ enhancer in which both AML-binding sites were mutated (Fig. 9D, TCR $\alpha \mathrm{mA}$ ). Taken together, these data indicate that the stimulation of TCR $\alpha$ enhancer activity by ALY is dependent on the presence of any two of the three lymphoid-specific factors LEF-1, AML-1, and Ets-1, presumably in combination with a member of the ubiquitously expressed CREB/ATF family. However, this 


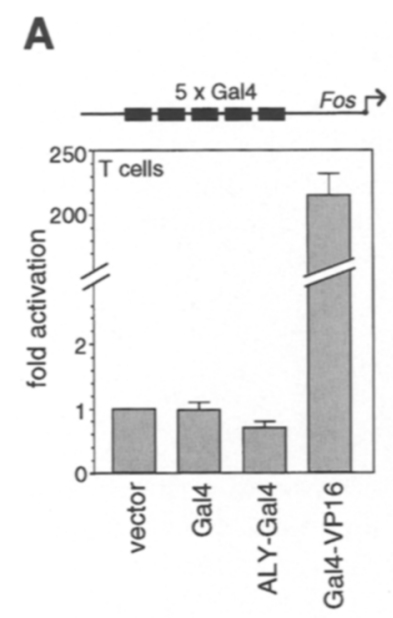

B
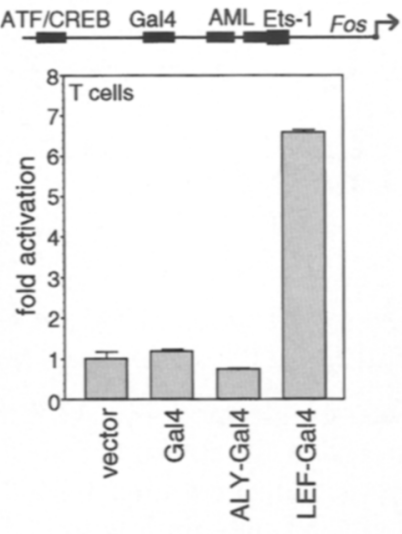

C

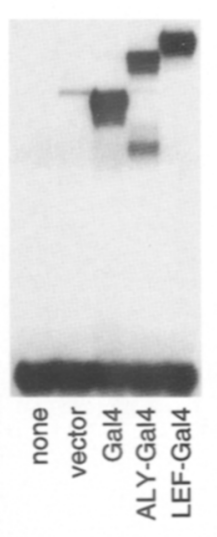

D

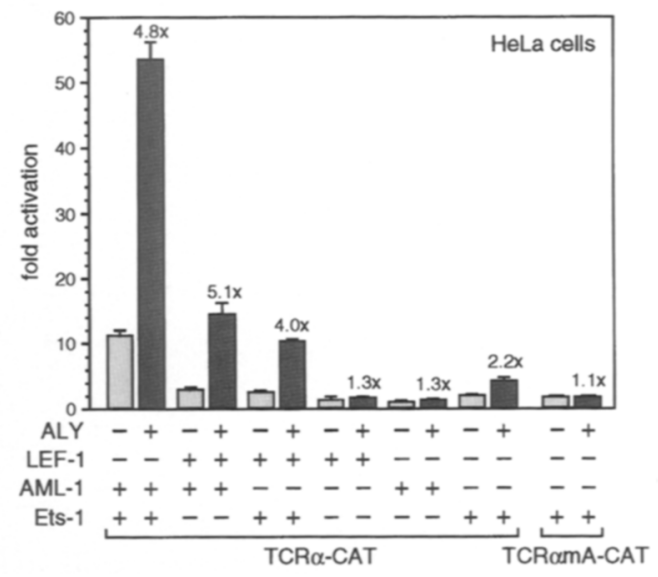

Figure 9. ALY stimulates transcription activation in the context of multiple TCR $\alpha$-enhancer binding proteins. (A) ALY-Gal4 does not activate from multimerized Gal4-binding sites. Jurkat $\mathrm{T}$ cells were transfected transiently with $2 \mu \mathrm{g}$ of a $(\mathrm{Gal} 4)_{5}-\mathrm{CAT}$ reporter, which contains five Gal4 sites linked to the minimal $\beta$-globin promoter, together with $2 \mu \mathrm{g}$ of CMV vector or expression plasmids for Gal4, ALY-Gal4, or Gal4-VP16. (B) ALY-Gal4 does not activate a TCR $\alpha$ enhancer construct in which the LEF-1 site is replaced by a Gal4 site. Jurkat $T$ cells were transfected with $1 \mu \mathrm{g}$ of reporter construct and $2.5 \mu \mathrm{g}$ of CMV vector or expression plasmids for Gal4, ALY-Gal4, or LEF-Gal4. Data are the average of at least two transfections carried out in duplicate; error bars represent standard error of the mean. $(C)$ Analysis of DNA binding of transfected Gal4, ALY-Gal4, and LEF-Gal4. Three micrograms of nuclear extracts from COS7 cells, transfected transiently with CMV vector or expression plasmids, were incubated with radiolabeled Gal-4 DNA-binding site and the protein-DNA complexes were analyzed in electrophoretic mobility-shift assays. (D) ALY stimulation of TCR $\alpha$ enhancer function requires any two of the lymphoid-specific factors LEF-1, AML-1, and Ets-1. HeLa cells were transfected transiently with different combinations of expression plasmids for AML (200 ng), Ets-1 (200 ng), and LEF-1 (100 ng) alone or together with $500 \mathrm{ng}$ of ALY expression plasmid. TCR $\alpha-$ CAT or TCR $\alpha \mathrm{mA}-\mathrm{CAT}(250 \mathrm{ng})$, which contains mutations in both AML-binding sites, were used as reporters. The numbers above the bars are the average fold difference between transfections with or without ALY expression plasmids.

stimulation appears to be independent of a simultaneous interaction of ALY with LEF-1 and AML-1.

\section{Discussion}

In this report, we present the identification and characterization of a ubiquitously expressed nuclear protein, termed ALY, that interacts specifically with two TCR $\alpha$ enhancer-binding factors, LEF-1 and AML-1. We find that overexpression of ALY in a reconstituted HeLa cell system stimulates the activity of the TCR $\alpha$ enhancer and that down-regulation of ALY using anti-sense oligonucleotides virtually abrogates TCR $\alpha$ enhancer activity in T cells. Thus, ALY seems to play a critical role in the function of the TCR $\alpha$ enhancer. Intriguingly, ALY interacts with domains of LEF-1 and AML- 1 that mediate transcriptional activation within a specific context of other DNA-bound factors. However, ALY does not seem to contain an activation domain capable of stimulating transcription when tethered to multimerized DNA sites through fusion to a Gal4 or LexA DNA-binding domain. This finding distinguishes ALY from typical coactivators that contain transcriptional activation domains. For example, CBP is a coactivator that interacts with both various transcription factors and TFIIB, a component of the basal transcription machinery (for review, see Janknecht and Hunter 1996). Another characteristic of ALY is its ability to stimulate DNA binding of transcription factors including LEF-1 and AML. We propose that ALY is a novel type of transcriptional regulator that may function to coordinate the activity of CADs within multiprotein enhancer complexes or to regulate the DNA-binding properties of proteins within the TCR $\alpha$ enhancer complex.

\section{ALY acts in the context of multiple TCR $\alpha$ enhancer-binding proteins}

The finding that ALY associates with both LEF-1 and AML proteins may account for the marked dependence of the TCR $\alpha$ enhancer on ALY. Down-regulation of ALY in $T$ cells by anti-sense oligonucleotides decreases the activity of the enhancer by at least 100 -fold. In contrast, mutations of individual factor-binding sites in the enhancer reduces its activity 5- to 10-fold /Giese et al. 1995). Thus, ALY may be important for the function of both LEF-1 and AML-1, and possibly other factors that participate in regulating the activity of the multiprotein TCR $\alpha$ enhancer complex. The context dependence of ALY function is reminiscent of the requirement of LEF-1 and AML-1 to act in a specific context of proteins. Part of the context dependence of LEF-1 can be attributed to the bending of DNA by the HMG domain of LEF-1 (Giese et al. 1992, 1995), but the activation domain of LEF-1 tethered to a heterologous DNA-binding domain also shows a context dependence (Carlsson et al. 1993; Giese and Grosschedl 1993). Part of the context-dependent function of AML-1 protein may reflect its direct interaction with Ets-1, which binds an adjacent site in the TCR $\alpha$ and TCR $\beta$ enhancers (Wotton et al. 1994; Giese et al. 1995; Sun et al. 1995). The ternary AML:Ets-1:DNA complex 
is, however, rather unstable and is, by itself, not competent to stimulate transcription from a minimal promoter (Giese et al. 1995). Therefore, additional interactions may be involved in mediating the context dependence of LEF-1 and AML proteins.

Although the interactions of ALY with both LEF-1 and AML-1 could, in principle, contribute to the context dependence by bridging these DNA-binding proteins, ALY also stimulates the activity of the TCR $\alpha$ enhancer in the absence of either LEF-1 or AML-1. Moreover, we failed to detect a further stabilization of the ALY:LEF-1:DNA ternary complex in vitro in the presence of $A M L$ or vice versa (data not shown). Thus, ALY may mediate transcriptional stimulation by facilitating the interaction of the CADs of LEF-1 and AML-1 with other components of the TCR $\alpha$ enhancer complex. In addition to the association with LEF-1 and AML-1, ALY shows some ability to interact weakly with members of the ATF/CREB family in vitro, raising the possibility that ALY may function to couple LEF-1 or AML-1, or both, to factors bound at the ATF/CREB site. Interestingly, the formation of the ternary complex of ALY with LEF-1 or AML proteins and DNA is dependent on the 98-bp TCR $\alpha$ enhancer fragment and is not observed with a 50-bp fragment that lacks sequences upstream of the LEF-1 binding site. These observations raise the possibility that ALY may also interact weakly with upstream sequences, although we did not detect a clear footprint in DNase I protection assays. Thus, ALY may participate in the multiple protein-protein and protein-DNA interactions involved in the TCR $\alpha$ enhancer complex, which, together, account for the context dependence of individual protein components.

\section{LEF-1-interacting proteins contribute to distinct transcriptional regulatory functions}

Consistent with the context-dependent function of ALY, interaction of this protein with LEF-1 does not mediate activation of transcription from multimerized LEF-1 binding sites (S.-C. Hsu and R. Grosschedl, unpubl.). However, another LEF-1-interacting protein, $\beta$-catenin, which has been shown recently to associate with the amino-terminal 76 residues of LEF-1 (Behrens et al. 1996; Huber et al. 1996), confers on LEF-1 and the related HMG-domain protein XTCF-3 the ability to stimulate transcription from multimerized sites, although $\beta$ catenin does not augment LEF-1 function at the TCR $\alpha$ enhancer (Behrens et al. 1996; Molenaar et al. 1996; S.-C. Hsu and R. Grosschedl, unpubl.). Thus, interactions of LEF-1 with distinct proteins mediate either context-dependent or context-independent regulatory functions.

$\beta$-Catenin is involved in both cell adhesion and the wnt signal transduction pathway, suggesting that LEF-1 may function as a nuclear target of this developmentally important signaling pathway. Consistent with this putative function of $L E F-1$, targeted inactivation of the Lef1 gene in the mouse resulted in severe developmental defects in the formation of tissues that express this gene during embryogenesis, including teeth, mammary glands, and hair follicles (van Genderen et al. 1994). Al- though targeted mutation of the Lef1 gene did not abrogate the expression of the TCR $\alpha$ gene (van Genderen et al. 1994), recent analysis of mice carrying a mutation in both the Lef1 gene and the closely related Tcf1 gene revealed a complete block in T-cell differentiation and a lack of TCR $\alpha$ gene expression (R. Okamura, H. Clevers, and R. Grosschedl, unpubl.). Thus, LEF-1 and TCF-1 may play redundant roles in regulating $\mathrm{TCR} \alpha$ gene expression in vivo. TCF-1 is significantly more abundant than LEF-1 in thymocytes (Travis et al. 1991; van de Wetering et al. 1991). However, TCF-1 is 10 -fold less efficient than LEF-1 in stimulating TCR $\alpha$ enhancer activity in transfected tissue culture cells (van de Wetering et al. 1996; L. Bruhn, unpubl.). Interestingly, TCF-1, which contains an HMG domain virtually identical to that of LEF-1, is divergent in the ALY-interacting region and ALY associates only weakly with TCF-1 (L. Bruhn, unpubl.). Thus, the ability of DNA-bound LEF-1 to interact stably with ALY may, at least in part, explain the higher efficiency of LEF-1 in stimulating TCR $\alpha$ enhancer function relative to TCF-1.

The ALY-interaction domain of $A M L-1$ is translocated in many leukemias

Studies of AML function have demonstrated that this protein plays an important role in transcriptional regulation of many targets in addition to TCR $\alpha$. The block in fetal liver hematopoesis displayed by mice carrying a targeted mutation in the $A M L-1$ gene demonstrates that AML-1 plays a role in regulating genes required for definitive hematopoiesis of all lineages (Okuda et al. 1996; Wang et al. 1996). The abundant expression of ALY observed in the fetal liver (L. Bruhn, unpubl.) is consistent with a possible role for ALY in mediating AML function at these putative targets. At least $25 \%$ of all childhood leukemias involve translocations in the genes encoding AML-1 or its heterodimeric DNA-binding partner $C B F \beta$ (for review, see Ito 1996). Interestingly, these translocations often replace the carboxy-terminal transcription activation domain of AML-1, which interacts with ALY, with segments of other proteins producing dominantnegative fusion proteins that can bind DNA strongly but do not activate transcription normally. To date, ALY is the only reported protein that interacts with the carboxyl terminus of AML-1, whereas all other known AML-interacting proteins, including CBF $\beta$, Ets- 1 , and $C / E B P$, associate with the Runt domain. In addition to its role at the TCR $\alpha$ enhancer, ALY may facilitate the function of AML-1 in combination with other proteins such as Myb and C/EBP, which have been shown to stimulate transcription in a synergistic manner with AML proteins at the TCR $\delta$ enhancer and the macrophage colony-stimulating factor receptor promoter, respectively (Hernandez-Munain and Krangel 1995; Zhang et al. 1996).

\section{Potential functions of $A L Y$ in regulating the TCR $\alpha$ enhancer}

The ability of ALY to bind weakly to RNA raises the 
possibility that, by analogy with HIV Tat protein (for review, see Jones and Peterlin 1994), ALY may stimulate gene expression by interacting with the nascent transcript. However, stimulation of the activity of the TCR $\alpha$ enhancer by ALY is observed with either the $t k$ or fos promoters linked to the bacterial CAT reporter gene (Fig. 7A; data not shown). Thus, ALY-mediated stimulation of the TCR $\alpha$ enhancer does not appear to require specific promoter or coding sequences.

The association of ALY with the CADs of LEF-1 and AML-1 can also occur with DNA-bound proteins, although the protein-protein interactions appear to be weak because high concentrations of ALY are required. One notable feature of the interaction of ALY with LEF-1 and AML is the 5- to 20-fold increase in DNA binding by both proteins. This effect of ALY on DNA binding involves the amino- and/or carboxy-terminal regions of ALY because ALY $\triangle N C$ does not increase DNA binding by LEF-1 or AML proteins. The stimulation of DNA binding by full-length ALY may be related to its potential to interact nonspecifically with nucleic acids. Consistent with this view, DNA binding by other proteins, such as c-Jun and glucocorticoid receptor that do not significantly interact with ALY, can also be augmented by addition of high concentrations of ALY in vitro (data not shown). However, the stimulation of transcription by ALY appears to require specific interaction domains because ALY does not stimulate the function of c-Jun or glucocorticoid receptor in transfection assays (Fig. 7B; data not shown).

Several proteins have been found to increase DNA binding by other factors. For example, $\operatorname{HMGI}(\mathrm{Y})$, a small basic DNA-binding protein, stably interacts with both

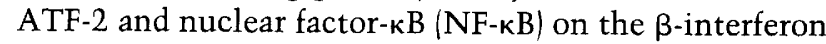
enhancer and increases DNA binding of these proteins and their assembly into a stereospecific multiprotein complex (Thanos and Maniatis 1992, 1995). The unrelated proteins HMG-1 and HMG-2 have also been shown to augment DNA binding of various proteins without participating in formation of a stable ternary complex (Onate et al. 1994; Zwilling et al. 1995). In addition, the protein hnRNP-K, which contains a $\mathrm{KH}$ motif RNAbinding domain and interacts with single-stranded nucleic acids, has been shown to interact with TATAbinding protein (TBP) in vitro and to function as a transcription factor in vivo (Michelotti et al. 1996). Finally, dimerization cofactor of hepatocyte nuclear factor 1 (DCoH), a transcriptional coactivator containing a potential RNP RNA-binding motif augments the dimerization and DNA binding by hepatocyte nuclear factor-1 (Mendel et al. 1991; Endrizzi et al. 1995). Taken together, these proteins appear to increase DNA binding by facilitating structural changes in DNA or proteins that accompany binding of individual proteins or the assembly of multiprotein complexes.

By analogy with these proteins, a simple model for ALY function at the TCR $\alpha$ enhancer could involve the increase of DNA binding by both LEF-1 and AML proteins. According to this view, the RNP motif of ALY, which mediates association with the CADs of LEF-1 and
AML-1, would recruit ALY into the enhancer complex to allow the basic RGG motifs of ALY to facilitate the structural distortion of DNA that accompanies binding by both LEF-1 and AML-1 (Giese et al. 1992; Love et al. 1995; Golling et al. 1996). However, this model of ALY function cannot account for all observations. First, ALY stimulates the activity of the TCR $\alpha$ enhancer in vivo by fivefold in the presence of both LEF-1 and AML-1 and a similar increase is observed when only one of these factors is present (Fig. 9D). Second, compared to the ALYmediated stimulation of DNA binding by either LEF-1 or AML proteins individually, ALY does not appear to further augment binding of both factors together in electrophoretic mobility-shift assays (data not shown). In addition, preliminary experiments suggest that addition of purified ALY protein to a mixture of LEF-1, AML-3, Ets1 , and ATF-2 or CREB is not sufficient to promote stable complex formation in DNase I footprint assays (A. Munnerlyn, unpubl.). Previously, we have shown that stable formation of the ternary AML:Ets-1:DNA complex is dependent on LEF-1 and HeLa cell nuclear extract, which may have provided the correct ATF/CREB family member or other factors required for stable complex formation (Giese et al. 1995).

Another possible, not mutually exclusive, model is that the association of ALY with the CADs of LEF-1 and AML-1 facilitates the coordination of multiple activation domains in the multiprotein TCR $\alpha$ enhancer complex. This stimulation could be mediated by direct interactions of a composite activation surface with basal factors or by recruitment of as yet unidentifed coactivators. Thus, ALY interaction with multiple TCR $\alpha$ enhancer-bound factors may be involved in the functional synergy observed between these factors. For both models ALY may be incorporated stably into the TCR $\alpha$ enhancer complex, possibly by operating as a molecular glue. Alternatively, ALY may act in a transient manner to facilitate interactions between multiple proteins or the DNA and may not be a structural part of the transcriptionally active multiprotein complex. Whatever molecular mechanism accounts for the function of ALY in regulating the TCR $\alpha$ enhancer, the association of ALY with the CADs of LEF-1 and AML-1, along with its observed functional properties, suggest that ALY may function to integrate and coordinate multiple protein-protein and/or protein-DNA interactions within specific higher order nucleoprotein complexes.

\section{Materials and methods}

Plasmids and oligonucleotides

Oligonucleotide-directed mutagenesis was used to replace the LEF-1 site in TCR $\alpha$-fos-CAT (Travis et al. 1991) with a Gal4binding site and to mutate the AML-binding sites (underlined) in TCR $\alpha \mathrm{mA}$-fos-CAT 5'-CTCatGaAGAActaACATCC; mutated residues are in lowercase letters. Plasmid CMV-AML-1 was generated by inserting a $B s a \mathrm{BI}-E c o \mathrm{RI}$ fragment from pKS+PEBP2 $\alpha$ B1 (Bae et al. 1994) into pEVRF0 (Matthias et al. 19891. pCMV-ALY and PCMV-T7-ALY were generated by inserting a Klenow-filled NcoI-XbaI fragment from p138-20z containing ALY cDNA, into the $S \mathrm{maI}$ site of $\mathrm{pEVRFO}$ and $\mathrm{pEVRFO-}$ 
T7. The latter vector contains coding sequences for the T7 epitope (MASMTGGQQMG). pCMV-ALY $\triangle$ NC contains an EagIBbsI fragment (codons 72-191) in pEVRFO. pCMV-ALY-Gal4 was constructed by inserting a fragment containing Gal4 codons 1-147 at a BglII site introduced at the stop codon of ALY by site-directed mutagenesis. Gal4(1-147) was also inserted into pEVRFO to create pCMV-Gal4. ${ }^{35}$ S-Labeled ALY protein was expressed in vitro from $\mathrm{p} 138-20 \mathrm{z}$ and full-length LEF-1 was expressed from pLS, which contains the SacI-KpnI fragment from pCG-LEF-1 (Giese and Grosschedl 1993) in Bluescript KS+ (Stratagene). Full-length mouse AML-1 was expressed from pKS+PEBP $2 \alpha B 1$ (Bae et al. 1994). Amino- and carboxy-terminal deletion derivatives of LEF-1 and AML-1 were constructed using naturally occurring restriction sites and PCR-generated fragments. Mouse AML-3(94-513) (Fig. 3) was expressed from pETPEBP $2 \alpha A 1(94-513)$ (K. Giese and R. Grosschedl, unpubl.). To construct pLEF-1-6His, a PCR-generated LEF-1 fragment was inserted into $p E T 23 d$ (Novagen) in-frame with a hexa-histidine tag. pGST-ALY $\triangle N C$ was constructed by inserting a SmaIEcoRI fragment that encodes 13 polylinker-derived residues followed by codons 76-177 of ALY into pGEX3x (Pharmacia). pGST-ALY was generated by inserting a NcoI-SacI fragment from p138-20z into pGEX-KG (Guan and Dixon 1991). The AML-3(94-411) protein used in Figure 6 was expressed from pET-PEBP2 $\alpha$ A1(94-411) (K.Giese and R. Grosschedl, unpubl.).

C-5 propyne pyrimidine-substituted phosphorothioate oligonucleotides used for the anti-sense experiments are as follows: The anti-sense ALY oligonucleotide (5'-GACATGTCCATTTTGTCGGC) is complementary to codons $2-8$ of the ALY transcript. The shuffled control oligonucleotide $\left(5^{\prime}\right.$-TCATGCGGTTGCATACGTCT) has the same base composition in a random order generated by the GCG sequence analysis program Shuffle.

\section{Yeast two-hybrid screen, cDNA isolation, and RNA analysis}

The LEF-1-LexA fusion construct (Giese and Grosschedl 1993) was subcloned into pBTM116 (Hollenberg et al. 1995) and the resulting plasmid was transformed into the yeast strain $\mathrm{L} 40$, which contains integrated lexA-lacZ and lexA-HIS3 reporter genes (Hollenberg et al. 1995). The mouse E10 (embryonic day 9.5-10.5) cDNA-VP16 fusion library, which contains inserts averaging $300 \mathrm{bp}$ in length, was screened using methods described in Hollenberg et al. (1995). From $2.7 \times 10^{6}$ original transformants, $200 \mathrm{HIS}^{+} / \mathrm{LacZ}^{+}$clones were isolated. Of these, 75 maintained expression of the reporter genes only in the presence of LEF-1-LexA. Library plasmids isolated from these clones were retransformed into strain $\mathrm{L} 40$ containing expression plasmids for LexA, LEF-1-LexA, LexA-lamin (Hollenberg et al. 1995), LexA-STE3, or LexA-FUS1 (kind gifts of S. Givens, B. Ferguson, and G. Sprague, University of Oregon, Eugene), to isolate eight cDNAs that encode peptides that interact specifically with LEF1. The 310-bp two-hybrid cDNA clone encoding ALY $\Delta N C$ was radiolabeled by random priming and used to screen a murine thymocyte cDNA library, a kind gift of $M$. Davis (Stanford University, CA). The sequence of a 1.1-kb cDNA clone $138-20 \mathrm{z}$ and the predicted amino acid sequence were compared with the GenBank DNA and protein databases using the blast algorithm (Altshul et al. 1990).

\section{Immunofluorescence and immunoblots}

COS7 cells were transfected transiently by electroporation with pCMV-T7-ALY and were allowed to settle onto poly-L-lysinecoated slides and incubated for $48 \mathrm{hr}$. Slides were processed as described in Travis et al. (1991). For immunodetection, T7 monoclonal antibody (Novagen) was used at a 1:1000 dilution, followed by a fluorescein isothiocyanate (FITC)-conjugated donkey anti-mouse antibody. 4,6-Diamidino-2-phenylindole (DAPI; $0.1 \mu \mathrm{g} / \mathrm{ml}$ ) was used to stain nuclei. Whole-cell extracts of Jurkat T cells transfected transiently with CMV-T7-ALY and antisense oligonucleotides were prepared by boiling and sonicating the cells in SDS-PAGE sample buffer. Extract from $2 \times 10^{6}$ cells was separated on $12.5 \%$ SDS polyacrylamide gels, transferred to nitrocellulose membrane, probed with $\mathrm{T} 7$ monoclonal antibody (Novagen) followed by peroxidase-conjugated goat anti-mouse secondary antibody (Cappel), and developed with Renaissance chemiluminescence reagent (DuPont NEN).

\section{Cell culture, transient transfections, and reporter gene assays}

COS7 and HeLa cells were cultured at $37^{\circ} \mathrm{C}$ in Dulbecco's modified Eagle medium, supplemented with $10 \%$ fetal calf serum (FCS). Lymphoid cells were grown in RPMI medium, supplemented with $10 \%$ FCS and $50 \mu \mathrm{M} 2$-mercaptoethanol. Transient transfections for the experiments shown in Figures 7 and 9 were performed by the DEAE-dextran/chloroquine procedure with the amounts of plasmids indicated in the figure legends and 250 ng of RSV- $\beta$-galactosidase control plasmid (Grosschedl and Baltimore 1985). Transfections of COS7 cells for the experiment of Figure $9 \mathrm{C}$ were performed by electroporation with $20 \mu \mathrm{g}$ of CMV expression plasmids. Anti-sense oligonucleotides were transfected with Lipofectin according to manufacturer's instructions (GIBCO-BRL). CAT, luciferase, and $\beta$-galactosidase assays were performed as described in Starr et al. (1996). After background subtraction, CAT or luciferase activity was normalized to the activity of the $\beta$-galactosidase internal transfection control.

\section{In vitro protein-protein association assays}

${ }^{35} \mathrm{~S}$-Labeled proteins were synthesized using a coupled transcription/translation (TnT) kit (Promega). GST fusion proteins immobilized on glutathione-agarose beads were incubated with radiolabeled proteins in binding buffer $[10 \mathrm{mM}$ Tris- $\mathrm{HCl}(\mathrm{pH} 8)$, $150 \mathrm{mM} \mathrm{NaCl}, 0.2 \% \mathrm{NP}-40,1 \mathrm{~mm}$ DTT, $0.2 \% \mathrm{BSA}]$ for $2 \mathrm{hr}$ at $4^{\circ} \mathrm{C}$. Beads were collected by centrifugation and washed four times with $1 \mathrm{ml}$ of binding buffer followed by one wash with 1 $\mathrm{ml}$ of binding buffer lacking BSA. Bound proteins were eluted from the beads by boiling in sample buffer [ $62.5 \mathrm{~mm}$ Tris- $\mathrm{HCl}$ (pH 6.8), 2\% SDS, $10 \%$ glycerol, $5 \%$-mercaptoethanol], separated by SDS-PAGE, and visualized by autoradiography. Where indicated, the GST and ${ }^{35} \mathrm{~S}$-labeled proteins were preincubated with $50 \mu \mathrm{g} / \mathrm{ml}$ pancreatic RNase (Boehringer Mannheim) for 15 min at $22^{\circ} \mathrm{C}$ before the association reactions. This amount of RNase was sufficient to eliminate the ribosomal RNA present in the in vitro translated ${ }^{35} \mathrm{~S}$-labeled proteins as detected by ethidium bromide staining.

\section{Protein purification, nuclear extracts, and DNA-binding analysis}

GST fusion proteins and the LEF-1-HMG domain polypeptide were overexpressed in bacteria and purified using glutathioneconjugated agarose beads essentially as described in Giese et al. (1995). The 6-His-tagged proteins LEF-1, AML-3 (94-411), and Runt were expressed in bacteria and purified using Ni-NTA agarose beads (Qiagen) according to manufacturer's instructions. Nuclear extracts of COS7 cells were prepared according to the method of Schreiber et al. (1989).

Electrophoretic mobility-shift assays and DNase I footprinting were performed as described by Travis et al. (1991). DNAbinding reactions contained $20 \mathrm{mM}$ HEPES buffer $(\mathrm{pH} 7.9), 75$ 
$\mathrm{mM} \mathrm{NaCl}, 1 \mathrm{~mm} \mathrm{DTT}, 2 \mathrm{mM} \mathrm{MgCl}{ }_{2}, 10 \%$ glycerol, $0.1 \mathrm{mg} / \mathrm{ml}$ of BSA, $5 \mu \mathrm{g} / \mathrm{ml}$ of salmon sperm DNA, $2.5 \mu \mathrm{g} / \mathrm{ml}$ of poly[d(I-C)], $\sim 10,000 \mathrm{cpm}$ (5 fmoles) labeled probe, and the amount of proteins or nuclear extract indicated in the figure legends. DNAbinding reactions with nuclear extract contained $50 \mathrm{\mu g} / \mathrm{ml}$ each of salmon sperm DNA and poly[d(I-C)]. For DNase I footprint analysis, the binding buffer also contained $0.5 \mathrm{~mm}$ spermidine.

\section{Acknowledgments}

We are thankful to R. Brazas, M. Davis, B. Ferguson, J. Fontes, S. Givens, S. Hollenberg, Y. Ito, K. Jones, U. Muller, F. Schaufele, and D.B. Starr for their kind donations of cDNA libraries, plasmids, and reagents. We thank George Farmer, Alan Frankel, Alexander Johnson, A. Kralli, and D. Barry Starr for their helpful suggestions on the manuscript, and members of the Grosschedl laboratory for valuable discussions. This work was supported, in part, by funds of the Howard Hughes Medical Institute and the National Institutes of Health. L.B. was supported by Cancer Research Institute and Arthritis Foundation postdoctoral fellowships.

The publication costs of this article were defrayed in part by payment of page charges. This article must therefore be hereby marked "advertisement" in accordance with 18 USC section 1734 solely to indicate this fact.

\section{Note added in proof}

The GenBank accession number for the sequence of ALY is U89876.

\section{References}

Altshul, S.F., W. Gish, W. Miller, E.W. Myers, and D.J. Lipman. 1990. Basic local alignment search tool. I. Mol. Biol. 215: 403-410.

Bae, S.C., E. Ogawa, M. Maruyama, H. Oka, M. Satake, K. Shigesada, N.A. Jenkins, D.J. Gilbert, N.G. Copeland, and Y. Ito. 1994. PEBP2 alpha B/mouse AML1 consists of multiple isoforms that possess differential transactivation potentials. Mol. Cell. Biol. 14: 3242-3252.

Bae, S.C., E. Takahashi, Y.W. Zhang, E. Ogawa, K. Shigesada, Y. Namba, M. Satake, and Y. Ito. 1995. Cloning, mapping and expression of PEBP $2 \alpha \mathrm{C}$, a third gene encoding the mammalian Runt domain. Gene 159: 245-248.

Behrens, J., J.P. von Kries, M. Kuhl, L. Bruhn, D. Wedlich, R. Grosschedl, and W. Birchmeier. 1996. Functional interaction of beta-catenin with the transcription factor LEF-1. Nature 382: 638-642.

Burd, C.G. and G. Dreyfuss. 1994. Conserved structures and diversity of functions of RNA-binding proteins. Science 265: 615-621.

Carlsson, P., M. Waterman, and K. Jones. 1993. The hLEF/TCF$1 \alpha$ HMG protein contains a context-dependent transcriptional activation domain that induces the TCR $\alpha$ enhancer in T cells. Genes \& Dev. 7: 2418-2430.

Endrizzi, J.A., J.D. Cronk, W. Wang, G.R. Crabtree, and T. Alber. 1995. Crystal structure of $\mathrm{DCoH}$, a bifunctional proteinbinding transcriptional coactivator. Science 268: 556-559.

Fields, S. and O.-K. Song. 1989. A novel genetic system to detect protein-protein interactions. Nature 340: 245-246.

Giese, K. and R. Grosschedl. 1993. LEF-1 contains an activation domain that stimulates transcription only in a specific context of factor-binding sites. EMBO F. 12: 4667-4676.

Giese, K., J. Cox, and R. Grosschedl. 1992. The HMG domain of lymphoid enhancer factor 1 bends DNA and facilitates as- sembly of functional nucleoprotein structures. Cell 69: 185195.

Giese, K., C.K. Kingsley, J.R. Kirshner, and R. Grosschedl. 1995. Assembly and function of a TCR $\alpha$ enhancer complex is dependent on LEF-1-induced DNA bending and multiple protein-protein interactions. Genes \& Dev. 9: 995-1008.

Golling, G., L. Li, M. Pepling, M. Stebbins, and J.P. Gergen. 1996. Drosophila homologs of the proto-oncogene product PEBP2/CBF beta regulate the DNA-binding properties of Runt. Mol. Cell. Biol. 16: 932-942.

Grosschedl, R. 1995. Higher-order nucleoprotein complexes in transcription: Analogies with site-specific recombination. Curr. Opin. Cell Biol. 7: 362-370.

Grosschedl, R. and D. Baltimore. 1985. Cell-type specificity of immunoglobulin gene expression is regulated by at least three DNA sequence elements. Cell 41: 885-897.

Grosschedl, R., K. Giese, and J. Pagel. 1994. HMG domain proteins: Architectural elements in the assembly of nucleoprotein structures. Trends Genet. 10: 94-100.

Guan, K.L. and J.E. Dixon. 1991. Eukaryotic proteins expressed in Escherichia coli: An improved thrombin cleavage and purification procedure of fusion proteins with glutathione Stransferase. Analytical Biochem. 192: 262-267.

Hernandez-Munain, C. and M.S. Krangel. 1995. c-Myb and corebinding factor/PEBP2 display functional synergy but bind independently to adjacent sites in the T-cell receptor $\delta$ enhancer. Mol. Cell. Biol. 15: 3090-3099.

Ho, I.-C. and J.M. Leiden. 1990. Regulation of the human T-cell receptor alpha gene enhancer: Multiple ubiquitous and $\mathrm{T}$ cell-specific nuclear proteins interact with four hypomethylated enhancer elements. Mol. Cell. Biol. 10: 4720-4727.

Hollenberg, S.M., R. Sternglanz, P.F. Cheng, and H. Weintraub. 1995. Identification of a new family of tissue-specific basic helix-loop-helix proteins with a two-hybrid system. Mol. Cell. Biol. 15: 3813-3822.

Holloway, J.M., D.P. Szeto, K.M. Scully, C.K. Glass, and M.G. Rosenfeld. 1995. Pit-1 binding to specific DNA sites as a monomer or dimer determines gene-specific use of a tyrosine-dependent synergy domain. Genes \& Dev. 9: 1992 2006.

Huber, O., R. Korn, J. McLaughlin, M. Ohsugi, B.G. Hermann, and R. Kemler. 1996. Nuclear localization of $\beta$-catenin by interaction with transcription factor LEF-1. Mech. Dev. 59: 3-10.

Ito, Y. 1996. Structural alterations in the transcription factor PEBP2/CBF linked to four different types of leukemia. $J$. Cancer Res. Clin. Oncol. 84: 321-330.

Janknecht, R. and T. Hunter. 1996. Transcriptional control: Versatile molecular glue. Curr. Biol. 6: 951-954.

Jones, K.A. and B.M. Peterlin. 1994. Control of RNA initiation and elongation at the HIV-1 promoter. Annu. Rev. Biochem. 63: $717-743$.

Kwok, R.P.S., J.R. Lundblad, J.C. Chrivia, J.P. Richards, H.P. Bachinger, R.G. Brennan, S.G.E. Roberts, M.R. Green, and R.H. Goodman. 1994. Nuclear protein CBP is a coactivator for the transcription factor CREB. Nature 370: 223-226.

Lai, J. and W. Herr. 1992. Ethidium bromide provides a simple tool for identifying genuine DNA-independent protein associations. Proc. Natl. Acad. Sci. 89: 6958-6962.

Landsman, D. and M. Bustin. 1993. A signature for the HMG-1 box DNA-binding proteins. BioEssays 15: 539-546.

Levanon, D., V. Negreanu, Y. Bernstein, I. Bar-Am, L. Avivi, and Y. Groner. 1994. AML1, AML2, and AML3, the human members of the runt domain gene-family: cDNA structure, expression, and chromosomal location. Genomics 23: 425432. 
Love, J.J., X. Li, D.A. Case, K. Giese, R. Grosschedl, and P.E. Wright. 1995. Structural basis for DNA bending by the architectural transcription factor LEF-1. Nature 376: 791-795.

Matthias, P., M.M. Muller, E. Schreiber, S. Rusconi, and W. Schaffner. 1989. Eukaryotic expression vectors for the analysis of mutant proteins. Nucleic Acids Res. 17: 6418-6419.

Mendel, D.B., P.A. Khavari, P.B. Conley, M.K. Graves, L.P. Hansen, A. Admon, and G.R. Crabtree. 1991. Characterization of a cofactor that regulates dimerization of a mammalian homeodomain protein. Science 254: 1762-1767.

Michelotti, E.F., G.A. Michelotti, A.I. Aronsohn, and D. Levens. 1996. Heterogeneous nuclear ribonucleoprotein $\mathrm{K}$ is a transcription factor. Mol. Cell. Biol. 16: 2350-2360.

Molenaar, M., M. van de Wetering, M. Oosterwegel, J. PetersonMaduro, S. Godsave, V. Korinek, J. Roose, O. Destree, and H. Clevers. 1996. XTcf- 3 transcription factor mediates $\beta$-catenin-induced axis formation in Xenopus embryos. Cell 86: $391-399$.

Nagai, K., C. Oubridge, N. Ito, J. Avis, and P. Evans. 1995. The RNP domain: A sequence-specific RNA-binding domain involved in processing and transport of RNA. Trends Biochem. Sci. 20: 235-240.

Ogawa, E., M. Maruyama, H. Kagoshima, M. Inuzuka, J. Lu, M. Satake, K. Shigesada, and Y. Ito. 1993a. PEBP2/PEA2 represents a family of transcription factors homologous to the products of the Drosophila runt gene and the human AML1 gene. Proc. Nat1. Acad. Sci. 90: 6859-6863.

Ogawa, E., M. Inuzuka, M. Maruyama, M. Satake, M. NaitoFujimoto, Y. Ito, and K. Shigesada. 1993b. Molecular cloning and characterization of PEBP2 $\beta$, the heterodimeric partner of a novel Drosophila runt-related DNA binding protein PEBP2a. Virology 194: 314-331.

Okuda, T., J. van Deursen, S.W. Hiebert, G. Grosveld, and J.R. Downing. 1996. AML1, the target of multiple chromosomal translocations in human leukemia, is essential for normal fetal liver hematopoiesis. Cell 84: 321-330.

Onate, S.A., P. Prendergast, J.P. Wagner, M. Nissen, R. Reeves, D.E. Pettijohn, and D.P. Edward. 1994. The DNA-bending protein HMG-1 enhances progesterone receptor binding to its target DNA sequences. Mol. Cell. Biol. 14: 3376-3391.

Ptashne, M. 1988. How eukaryotic transcriptional activators work. Nature 335: 683-689.

Satake, M., S. Nomura, Y. Yamaguchi-Iwai, Y. Takahama, Y. Hashimoto, M. Niki, Y. Kitamura, and Y. Ito. 1995. Expression of the Runt domain-encoding PEBP $2 \alpha$ genes in T cells during thymic development. Mol. Cell. Biol. 15: 1662-1670.

Schreiber, E., P. Matthias, M. Muller, and W. Schaffner. 1989. Rapid detection of octamer binding proteins with "mini-extracts" prepared from small number of cells Nucleic Acids Res. 17: 6419.

Sheridan, P.L., C.T. Sheline, K. Cannon, M.L. Voz, M.J. Pazin, J.T. Kadonaga, and K.A. Jones. 1995. Activation of the HIV-1 enhancer by the LEF-1 HMG protein on nucleosome-assembled DNA in vitro. Genes \& Dev. 9: 2090-2104.

Starr, D.B., W. Matsui, J.R. Thomas, and K.R. Yamamoto. 1996. Intracellular receptors use a common mechanism to interpret signaling information at response elements. Genes \& Dev. 10: 1271-1283.

Sun, W., B. Graves, and N.A. Speck. 1995. Transactivation of the Moloney murine leukemia virus and T-cell receptor $\beta$-chain enhancers by $c b f$ and $e t s$ requires intact binding sites for both proteins. J. Virol. 69: 4941-4949.

Tanaka, T., K. Tanaka, S. Ogawa, M. Kurokawa, K. Mitani, J. Nishida, Y. Shibata, Y. Yazaki, and H. Hirai. 1995. An acute myeloid leukemia gene, AMLl, regulates hemopoietic myeloid cell differentiation and transcriptional activation an- tagonistically by two alternative spliced forms. EMBO $\mathrm{J}$. 14: 341-350.

Thanos, D. and T. Maniatis. 1992. The high mobility group protein $\mathrm{HMGI}(\mathrm{Y})$ is required for NF-kB-dependent virus induction of the human IFN- $\beta$ gene. Cell 71: 777-789.

- 1995. Virus induction of human IFN beta gene expression requires the assembly of an enhanceosome. Cell 83: $1091-1100$.

Tjian, R. and T. Maniatis. 1994. Transcriptional activation: A complex puzzle with few easy pieces. Cell 77: 5-8.

Travis, A., A. Amsterdam, C. Belanger, and R. Grosschedl. 1991. LEF-1, a gene encoding a lymphoid-specific protein with an HMG domain, regulates T-cell receptor $\alpha$ enhancer function. Genes \& Dev. 5: 880-894.

van de Wetering, M., M. Oosterwegel, D. Dooijes, and H. Clevers. 1991. Identification and cloning of TCF-1, a T lymphocyte-specific transcription factor containing a sequence-specific HMG box. EMBO I. 10: 123-132.

van de Wetering, M., J. Castrop, V. Korinek and H. Clevers. 1996. Extensive alternative splicing and dual promoter usage generate Tcf-1 protein isoforms with differential transcription control properties. Mol. Cell. Biol. 16: 745-752.

van Genderen, C., R.M. Okamura, I. Farinas, R.-G. Quo, T.G. Parslow, L. Bruhn, and R. Grosschedl. 1994. Development of several organs that require inductive epithelial-mesenchymal interactions is impaired in LEF-1-deficient mice. Genes \& Dev. 8: 2691-2703.

Wagner, R.W., M.D. Matteucci, J.G. Lewis, A.J. Gutierrez, C. Moulds, and B.C. Froehler. 1993. Antisense gene inhibition by oligonucleotides containing $\mathrm{C}-5$ propyne pyrimidines. Science 260: 1510-1513.

Wang, Q., T. Stacy, M. Binder, M. Marin-Padilla, A.H. Sharpe, and N.A. Speck. 1996. Disruption of the Cbf $\alpha 2$ gene causes necrosis and hemorrhaging in the central nervous system and blocks definitive hematopoiesis. Proc. Natl. Acad. Sci. 16: 3444-3449.

Wang, S., Q. Wang, B. Crute, I. Melnikova, S. Keller, and N. Speck. 1993. Cloning and characterization of subunits of the T-cell receptor and murine leukemia virus enhancer corebinding factor. Mol. Cell. Biol. 13: 3324-3339.

Waterman, M. and K. Jones. 1990. Purification of TCF- $1 \alpha$, a T cell-specific transcription factor that activates the $\mathrm{T}$-cell receptor $\mathrm{C} \alpha$ gene enhancer in a context-dependent manner. New Biol. 2: 621-636.

Waterman, M.L., W.H. Fischer, and K.A. Jones. 1991. A thymusspecific member of the HMG protein family regulates the human T cell receptor $\alpha$ enhancer. Genes \& Dev. 5: 656-669.

Wotton, D., J. Ghysdael, S. Wang, N. Speck, and M. Owen. 1994. Cooperative binding of Ets-1 and core binding factor to DNA. Mol. Cell. Biol. 14: 840-850.

Zhang, D.-E., C.J. Hetherington, S. Meyers, K.L. Rhoades, C.J. Larson, H.-M. Chen, S.W. Hiebert, and D.G. Tenen. 1996 CCAAT enhancer-binding protein (C/EBP) and AML1 (CBFa2) synergistically activate the macrophage colonystimulating factor receptor promoter. Mol. Cell. Biol. 16: $1231-1240$.

Zwilling, S., H. Konig, and T. Wirth. 1995. High mobility group protein 2 functionally interacts with the POU domains of octamer transcription factors. EMBO T. 14: 1198-1208. 


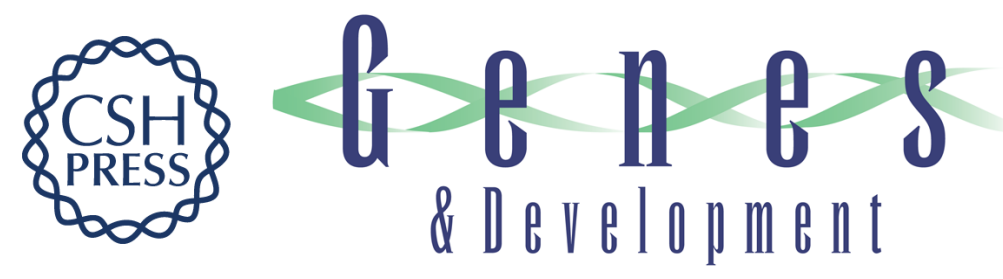

\section{ALY, a context-dependent coactivator of LEF-1 and AML-1, is required for TCRalpha enhancer function.}

L Bruhn, A Munnerlyn and R Grosschedl

Genes Dev. 1997, 11:

Access the most recent version at doi:10.1101/gad.11.5.640

References This article cites 60 articles, 27 of which can be accessed free at: http://genesdev.cshlp.org/content/11/5/640.full.htmI\#ref-list-1

License

Email Alerting

Receive free email alerts when new articles cite this article - sign up in the box at the top Service right corner of the article or click here.

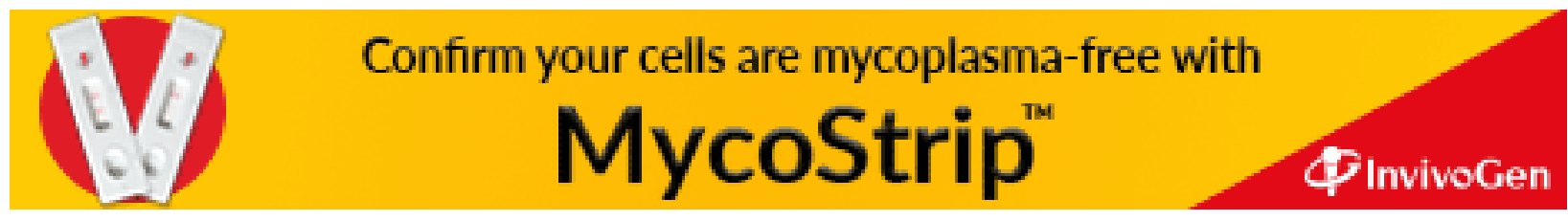

